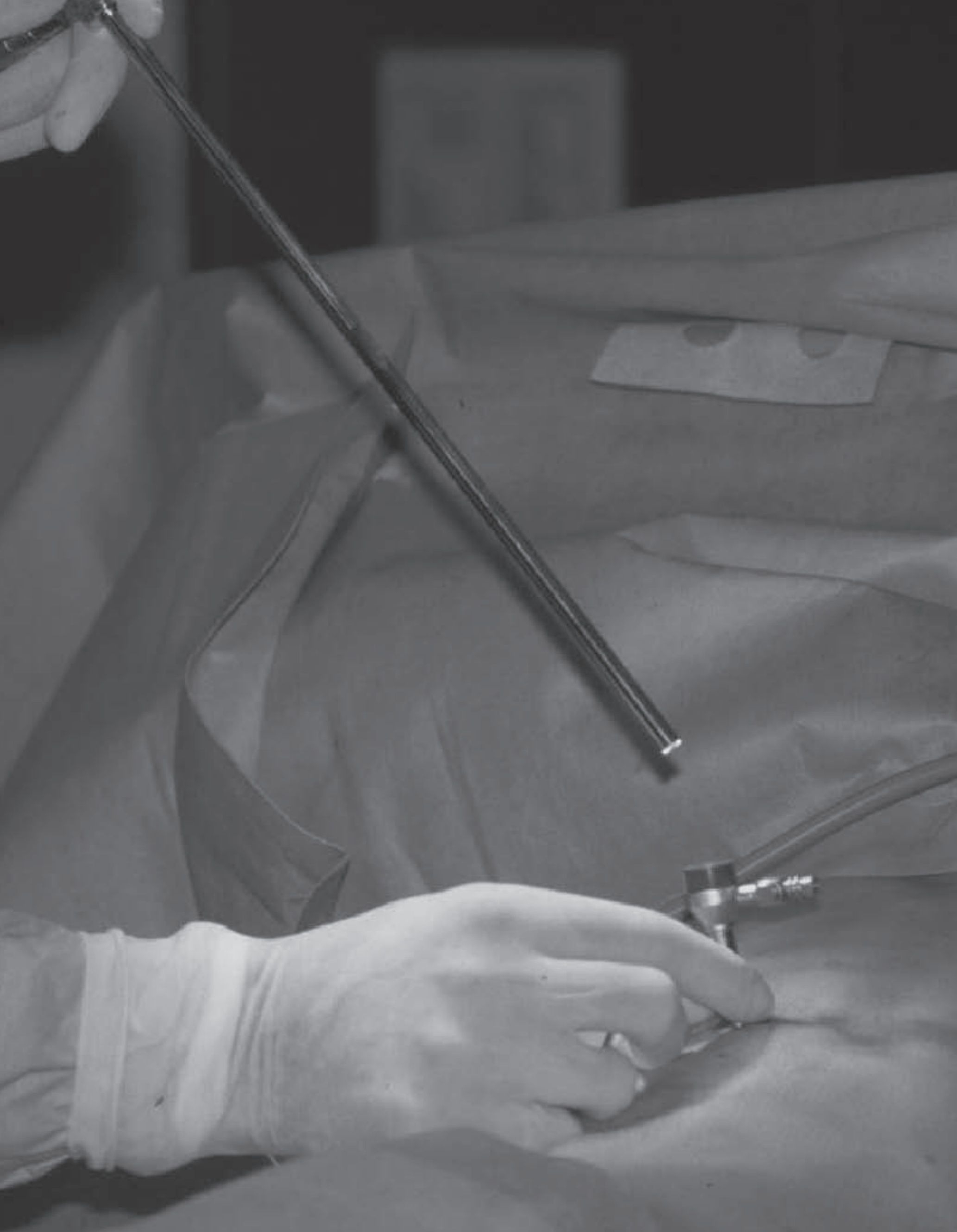

Image: reproduced from Eur Respir Mon 2010; 48: 119-132 with permission from the publisher. 


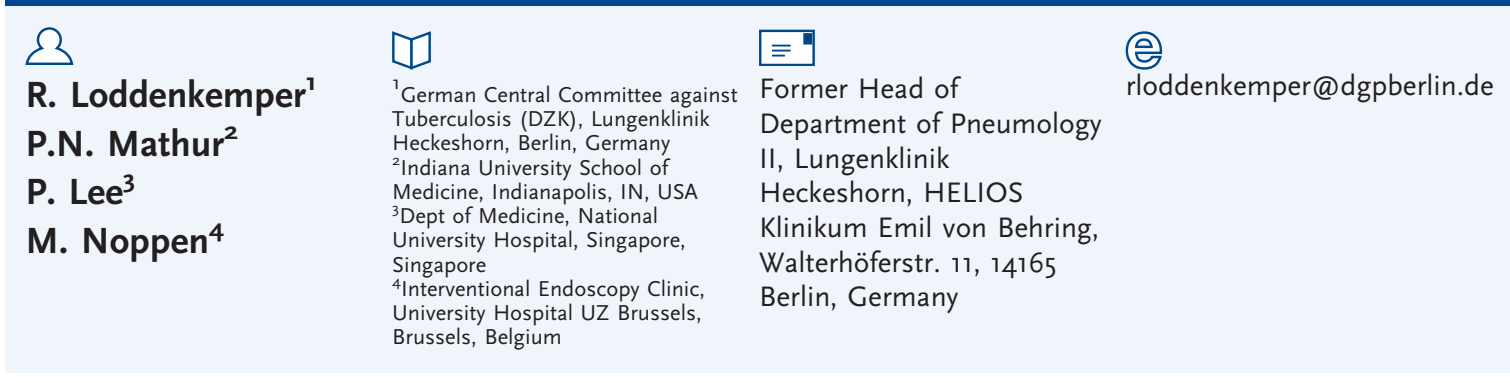

\section{History and clinical use of thoracoscopy/pleuroscopy in respiratory medicine}

\section{Summary}

Thoracoscopy was introduced over 100 years ago and for 40 years has been mainly used in the pneumothorax treatment of tuberculosis in those cases where pleuro-pulmonary adhesions prevented collapse of the lung. In the 1950s, the pneumothorax treatment of tuberculosis came to an end and thoracoscopy was used in a few centres by chest physicians as a diagnostic and therapeutic method in several pleuro-pulmonary diseases. In the 1990s, thoracic surgeons introduced the technique for minimally invasive surgery, known as "surgical thoracoscopy" or more precisely "video-assisted thoracic surgery" (VATS), which is performed under general anaesthesia with one-lung ventilation. In contrast, medical thoracoscopy/pleuroscopy can be performed under local anaesthesia or conscious sedation, in an endoscopy suite, using non-disposable rigid or semi-rigid instruments. Thus, it is considerably less invasive and less expensive. Today, medical thoracoscopy/ pleuroscopy is increasingly used by chest physicians, mainly in patients with pleural effusion or pneumothorax including talc poudrage as best conservative pleurodesis treatment. Meanwhile, the technique is considered to be one of the main areas of interventional pneumology.

\section{Introduction}

Thoracoscopy was introduced over 100 years ago by Hans-Christian Jacobaeus from Sweden [1] and has become today the second most important endoscopic technique in respiratory medicine after bronchoscopy [2]. Jacobaeus developed thoracoscopy primarily as a diagnostic method and described the technique, together with laparoscopy, in a paper entitled "On the possibility to use cystoscopy in the
Statement of interest None declared.

HERMES syllabus link: module D.2.10 
examination of serous cavities" [1]. At that time, as a result of the development of suitable optical systems in the 19th century, endoscopy was already being applied to all organs and cavities with anatomical connections to the exterior.

However, recently it was reported that Francis Richard Cruise in Ireland was probably the first to perform thoracoscopy as early as 1866 [3]. Cruise, who in 1865 had already published "Endoscope as an aid to the diagnosis and treatment of disease" [4], performed an "examination of interior of pleura by endoscope" in an 11-year-old girl with empyema through a pleurocutaneous fistula that had developed after pleural drainage. He used the technique for monitoring the therapy in this girl. Although this was published in the Dublin Quarterly Journal of Medical Science in 1866 [5], the technique remained anecdotal.

Yet, Hans-Christian Jacobaeus must be regarded as the father of thoracoscopy. In his pioneer paper published in German in the Münchener Medizinische Wochenschrift [1], he mentioned two cases of tuberculous pleural effusion (pleuritis exudativa), in which he studied the pleural surfaces after replacing fluid with air. He used a cystoscope for inspection of the pleural cavity and mentioned three main prerequisites for the technique, still valid today: 1) the possibility to introduce a trocar without lacerating the inner organs and without causing too much pain; 2) introduction of a transparent medium into the cavity (Jacobaeus used filtered air for this purpose); and 3) a cystoscope of such small dimensions that it could be introduced through the trocar.

In the following years, Jacobaeus and several other European pulmonary specialists from Scandinavia, Germany, Italy and other European countries performed thoracoscopy for diagnostic purposes in pleural effusions, spontaneous pneumothorax, focal pulmonary diseases, diseases of the chest, mediastinal tumours, as well as anomalies of the heart and great vessels and thoracic trauma [6, 7]. Jacobaeus himself in 1912 published an extensive description of the technique and the results of thoracoscopy (and laparoscopy) [8], and finally in 1925, a comprehensive summary of his experiences describing in detail his studies on the aetiology and staging of tuberculous pleurisy, malignant effusion, rheumatoid effusion, empyema, parapneumonic effusion and idiopathic pneumothorax [9].

\section{Thoracoscopy as a therapeutic procedure in tuberculosis: "Jacobaeus Operation"}

In his pioneer paper, Jacobaeus had already cited Forlanini's method by which air or nitrogen was blown into the pleural space and induced collapse of the lung, known as pneumothorax treatment of tuberculosis. As early as 1913, Jacobaeus applied thoracoscopy in those cases with adhesions, preventing the collapse of the lung. He performed lysis of adhesions by a thoracocautery, which was introduced through a second entry [10].

The technique, named "Jacobaeus Operation", subsequently spread around the world and, during the ensuing 45 years, thoracoscopy was almost exclusively used for lysis of pleural effusions in the treatment of tuberculosis [11].

\section{Thoracoscopy as a therapeutic tool in non- tuberculous diseases}

Anton Sattler, in Vienna, was probably the first (in 1937) to use thoracoscopy in the treatment of patients with idiopathic spontaneous pneumothorax [11]. Subsequently, many others, again mainly in Europe, used a similar technique for this indication: with thoracoscopy, bleeding from torn adhesions or bronchopleural fistulas could be cauterised by electrocoagulation, adhesions preventing the closure of ruptured blebs could be divided, and localised pleurodesis could be undertaken [12].

Kux in Germany used the technique in 1947 in the treatment of hyperhidrosis by sympathectomy [13]. He also described vagotomy for other indications.

Jacobaeus in 1925 had already demonstrated the use of thoracoscopy in patients with empyema [9]. Some authors later applied the method for treatment of empyema, by breaking up loculations of pus and by removing fibrinopurulent membranes, thus creating a single cavity that could by drained and irrigated with high efficiency [14].

In 1963, Roche and co-workers, in France, were presumably the first to report on talc poudrage during thoracoscopy as a means of 
achieving pleurodesis in chronic, mainly malignant pleural effusions [15]. This thoracoscopic technique is now widely accepted as gold standard of pleurodesis due to its high success rate [16], and is also used successfully in pneumothorax patients [17].

\section{Further development of thoracoscopy as a diagnostic tool in the I950}

In the years between 1950 and 1960, with the advent of antibiotic treatment for tuberculosis, the era of pneumothorax therapy of pulmonary tuberculosis came to an end [11]. In addition, as the number of tuberculosis patients in industrialised countries gradually declined, other pleuro-pulmonary diseases became more important to the chest physician. Consequently, a generation of physicians already familiar with the therapeutic application of thoracoscopy began to use this technique on a much broader basis for diagnostic evaluation of different chest diseases [18].

The indications for thoracoscopy were greatly expanded by the use of various biopsy techniques for localised and diffuse lung diseases. Several authors (Sattler, Brandt, Swierenga, Boutin, Viskum in Europe and Storey and Bloomberg in the USA) studied large numbers of patients and published the data [11]. The first atlas of colour photographs of thoracoscopy was published by Swierenga in 1978 [19], followed by the Atlas of Diagnostic Thoracoscopy published by Brandt and co-workers in 1985 [11], and the book Practical Thoracoscopy published by Boutin's group in 1991 [20].

Pneumologists nowadays use two different techniques for the performance of diagnostic and therapeutic thoracoscopy. One method recommends a single-entry site, the use of a usually $9-\mathrm{mm}$ rigid thoracoscope (or of a semirigid/semi-flexible 7-mm pleuroscope) with a working channel for accessory instruments and an optical biopsy forceps, both performed under local anaesthesia. The other method requires two entry sites: one for a 7-mm trocar for the examination telescope, and the other for a 5-mm trocar for accessory instruments including the biopsy forceps, and is usually performed with conscious sedation or general anaesthesia $[18,20]$. The rigid instruments are developed respectively, by Karl Storz $\mathrm{GmbH}$ and Richard Wolf GmbH, two German companies, and the semi-flexible pleuroscope by the Japanese company Olympus.

\section{Development of} thoracoscopy for minimally invasive surgery: surgical thoracoscopy/VATS

In the early 1990s, advances in abdominal minimally invasive surgery stimulated thoracic surgeons to try this technique in surgery for pleuro-pulmonary disorders as well (Inderbitzi, Kaiser, Landreneau, Lewis, LoCicero, McKenna, Miller and others) [18]. The technique was called "therapeutic/surgical thoracoscopy" as well as "video-controlled/video-thoracoscopic surgery", "minimally invasive", or "VATS" [18].

VATS requires general anaesthesia with selective endobronchial intubation and usually at least three points of entry. It is in fact a surgical procedure for which an operating theatre and disposable, often expensive, instruments are needed. Meanwhile, it can replace thoracotomy in almost all indications [18].

In the USA, where only a few pulmonary physicians performed thoracoscopy, a heated debate ensued about whether thoracoscopy should be performed by pulmonologists or be limited to the domain of the thoracic surgeon. In the meantime, American surgeons agree that medical thoracoscopy/pleuroscopy is in the domain of pulmonologists but correctly insist that adequate training is essential [21]. There is no doubt that a strong professional relationship between the pulmonologist and the thoracic surgeon must be maintained. In most parts of Europe, this was not a controversial issue, as many pneumologists had been performing thoracoscopy well before the introduction of VATS [22].

\section{Nomenclature}

For better distinction, the term "medical thoracoscopy" was introduced in 1994 [23]. However, since the term "thoracoscopy" is still used to describe both the medical and the surgical procedure, a certain amount of confusion has arisen and persists. This possibly has led and still leads to some unnecessary surgical interventions for what are or should in fact be medical indications. To avoid continuing confusion, it has been proposed "for the 
sake of clarity" to return to the old term "pleuroscopy" [24], already introduced in France in 1923 [25]. However, there is no uniform opinion among respiratory physicians; some feel that the term "medical" is not appropriate, since thoracoscopy will always be an invasive procedure [26]. But this does not solve the dilemma. The approach of the physician should be distinguished from the very different surgical approach, which would be best defined as "VATS". However, the term "pleuroscopy" has now become quite popular with the introduction of the semi-rigid (semiflexible, flex-rigid) pleuroscope by Olympus Corporation. Today, both terms, "medical thoracoscopy" and "pleuroscopy", are therefore used as synonyms. Other terms used are "thoracoscopy for physicians" [27], "thoracoscopy for chest physicians" and "local anaesthetic thoracoscopy" [28].

\section{Introduction of the semi- flexible pleuroscope}

Flexible bronchoscopes had already been used for thoracoscopies, mainly by pulmonologists in North America. Several case reports from 1975 describe this technique, which had been termed "pleuroscopy" as well [11]. Presumably, these flexible bronchoscopes were used because more suitable instruments were not generally available. However, flexible bronchoscopes showed several disadvantages, mainly that they provide less adequate orientation within the pleural cavity, since a fixed anatomical guidance as in the tracheobronchial tree is not present and that the biopsies are much smaller $[29,30]$. Special semi-flexible instruments with rigid shafts and flexible tips were developed in Japan as early as 1978 by Takeno, a surgeon who used them in pneumothorax treatment [31]. In 1998, a semi-flexible thoracofibrescope was used by MacLean and coworkers in pleural effusions; the pleura was well visualised, but the working channel of $2 \mathrm{~mm}$ was felt to be somewhat too small [32]. The next generation was again developed by Olympus Corporation in 2002 [33], with a working channel of $2.8 \mathrm{~mm}$ and incorporated video imaging. In 2007, the autoclavable semi-rigid/semi-flexible thoracoscope was introduced [34].

The advantage of the semi-flexible pleuroscope is that it has the look and feel of a flexible bronchoscope, and thus may lower the threshold for medical thoracoscopy for chest physicians [35, 36]. It may also be helpful psychologically in overcoming fear of using the rigid (and therefore often regarded as more dangerous) instruments. It interfaces easily with existing processors and light sources made by the manufacturer for flexible bronchoscopy or endoscopy, which are available in most endoscopy units without additional costs. Its flexible tip can be manoeuvred in different directions and around adhesions, and it facilitates the homogeneous insufflation of talc. It maintains a clear optical field by allowing concurrent suctioning, which is analogous to the suction techniques used during flexible bronchoscopy $[18,36]$. However, the specimens obtained with the rigid instruments are significantly larger. The rigid forceps allows the taking of biopsies from very dense lesions as well, and the rigid instruments are more suitable when more elaborate procedures are indicated (e.g. extensive adhesiolysis, visceral pleural/lung biopsies, sympathicolysis) $[26,37]$.

Recently, rigid minithoracoscopes as a less invasive technique have been used $[38,39]$, but are much less suited for thoracoscopy since they have the disadvantages that a second point of entry is necessary for biopsy purposes and that insertion of a large drainage catheter through the same channel is not possible [40].

\section{Clinical use of medical thoracoscopy/pleuroscopy}

Medical thoracoscopy/pleuroscopy is currently primarily a diagnostic procedure, but it can also be applied for therapeutic purposes $[15,22,26$, $35,37,41,42]$. As such, it is meanwhile considered to be one of the main areas of interventional pulmonology [2]. Since it is an invasive procedure that the chest physician should use only when other, simpler methods fail to yield a diagnosis or when less invasive therapeutic measures are not available or less promising, a careful evaluation of the patient as well as of the indications and contraindications to the procedure is mandatory [18].

\section{Pleural effusions}

Besides diagnosis, patients with pleural disorders may require evacuation of pleural fluid, guided parietal pleural biopsies, lung biopsies 
or pleurodesis [43-45]. Medical thoracoscopy/ pleuroscopy has its main role in the invasive diagnosis of otherwise undetermined pleural effusions and in local treatment $[26,42]$.

The advantages of medical thoracoscopy/ pleuroscopy in the diagnosis of pleural effusions are fast and definite biopsy diagnosis including TB culture and hormone receptor assay, biopsies not only from chest wall pleura but also from diaphragm, lung and mediastinum, staging in lung cancer and diffuse mesothelioma, and exclusion of malignancy in tuberculosis with high probability $[18,42]$. Furthermore, the technique has to be considered as the gold standard for scientific studies and pleural effusions. The advantages in the treatment of pleural effusions are complete and immediate fluid removal (even of several litres), evaluation of loculations (TB, empyema), microscopic evaluation of the reexpansion potential of the lung and talc poudrage for pleurodesis with uniform distribution of talc under visual control [37, 42].

\section{Malignant pleural effusions}

Medical thoracoscopy/pleuroscopy has a much higher diagnostic sensitivity and specificity than fluid cytology and closed needle biopsy combined. Therefore, in cases of undiagnosed exudative effusions with a high clinical suspicion for malignancy, some clinicians may proceed directly to medical thoracoscopyl pleuroscopy if cytology is negative and if the facilities for medical thoracoscopy/pleuroscopy are available [46]. A theoretical cost analysis in the UK showed that medical thoracoscopy/ pleuroscopy may save considerable costs in unexplained pleural effusions compared with image-guided pleural biopsy [47].

In a prospective intrapatient comparison, the diagnostic yield of the non-surgical biopsy methods in malignant pleural effusions was studied simultaneously in 208 patients, including 58 diffuse malignant mesotheliomas, 26 cancers of the lung, 116 metastatic pleural effusions with 38 breast cancers, 30 cancers of various other origins, 58 of undetermined origin and five malignant lymphomas [42]. The overall diagnostic yield with cytological results from effusion was $62 \%$, with needle biopsy (true-cut) $44 \%$, and with medical thoracoscopy/pleuroscopy $95 \%$; the latter showing a significantly higher sensitivity than needle biopsy with cytological results from effusions combined, which were positive in
$74 \%$ of cases (fig. 1). In an additional study on 287 cases with malignant pleural effusion [46], there was virtually no difference in the yield of medical thoracoscopy for the different types of malignant effusions. The overall yield was $62 \%$ for cytology and $95 \%$ for medical thoracoscopy/ pleuroscopy; the yield for cytology and in particular thoracoscopy did not vary much between lung carcinomas ( 67 versus $69 \% ; n=67$ ), extrathoracic primaries ( 62 versus $95.5 \%$; $n=154$ ), or diffuse malignant mesotheliomas (58 versus $92 \% ; n=66)$. Similar results were reported by several other investigators [37, 43, 48].

A further advantage of medical thoracoscopy/pleuroscopy in malignant pleural diseases is that biopsies can be taken under direct visual control not only of the costal pleura but also of the visceral and diaphragmatic pleura [18]. The larger tissue specimens provide an easier histological/immunohistological identification of the primary tumour, including determination of hormone receptors in breast cancer [49], and a better morphological classification in lymphomas [50] and in their differential diagnosis [51]. In addition, medical thoracoscopy/pleuroscopy is helpful in staging of lung cancer, diffuse malignant mesothelioma, and metastatic cancers $[46,52]$. In lung cancer patients, it can be better determined whether the tumour has spread to the pleura, or is secondary to venous or lymphatic obstruction, or paramalignant, e.g., to pneumonia. As a result, it may be possible to avoid exploratory thoracotomy or to determine operability [46].

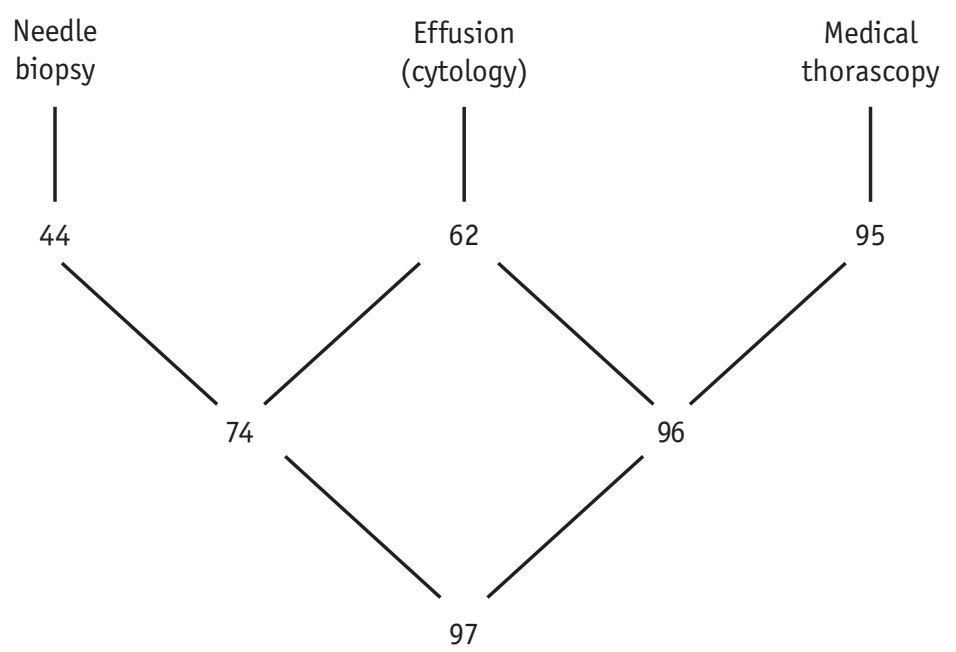

Figure 1

The different sensitivities (\%) of biopsy techniques used in the diagnosis of malignant pleural effusions (cytological and histological results combined). Taken from [42]. 
In diffuse malignant mesothelioma, medical thoracoscopy/pleuroscopy can more often and more precisely provide a histological classification than closed pleural biopsy because of larger and more representative biopsies, along with more accurate staging $[53,54]$.

Reasons for false-negative results include insufficient and non-representative biopsies, which depend largely on the experience of the thoracoscopist, and the presence of adhesions that deny access to neoplastic tissue $[55,56]$. Autofluorescence video thoracoscopy with rigid instruments, developed by Richard Wolf $\mathrm{GmbH}$ in Germany, may help in future to avoid some of the false-negative results [57]. Narrowband imaging during semi-rigid pleuroscopy, developed by Olympus Corporation, Japan, may also earlier detect discreet pathological changes [58-6o].

The main additional advantage in using medical thoracoscopy/pleuroscopy to diagnose malignancy is that talc poudrage can be performed during the same procedure, which has higher success rates of more than $80 \%[61,62]$. An even distribution of the talc powder to all parts of the pleura can be achieved by poudrage under visual control. Furthermore, by visual inspection it can be judged whether the lung will re-expand, which is an important prerequisite for successful pleurodesis [18].

\section{Tuberculous pleural effusions}

Although the diagnostic yield of closed needle pleural biopsies is much better than in malignant pleural effusions due to the usually more disseminated involvement of the whole pleural surface, medical thoracoscopy/pleuroscopy has a higher histological and bacteriological yield [63]. In a prospective intrapatient comparison,

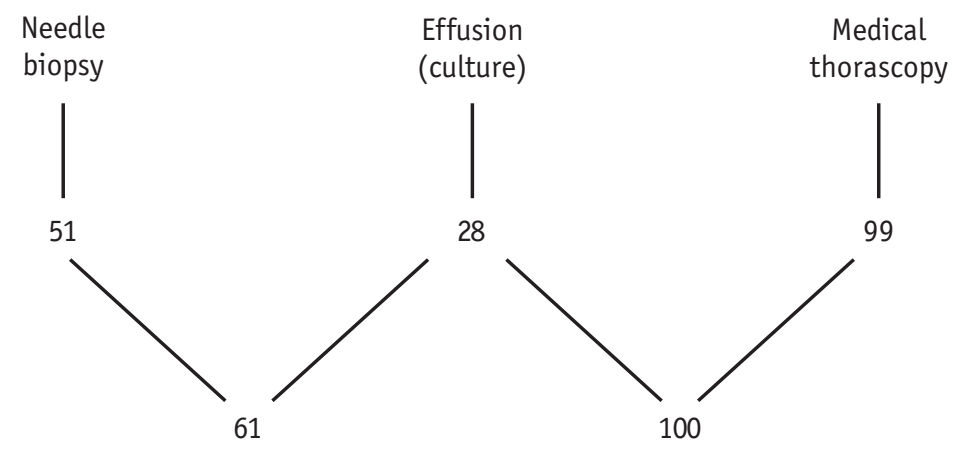

Figure 2

The different sensitivities (\%) of biopsy techniques used in the diagnosis of tuberculous pleural effusions (histological and bacteriological results combined). Taken from [42]. an immediate diagnosis in 100 TB cases could be established histologically by medical thoracoscopy/pleuroscopy in $94 \%$, compared with needle biopsy (true-cut) with only $38 \%$ positive results [64]. In individual cases, this may be of clinical importance because antituberculous treatment can be started without delay. The combined yield of histology and bacteriological culture was positive for medical thoracoscopy/ pleuroscopy in $99 \%$ and for needle biopsy in $51 \%$, and when culture results from effusions were added, in $61 \%$ of cases. The percentage of positive TB cultures was twice as high from thoracoscopic biopsies, including cultures from fibrinous membranes (78\%), which are always worth examining, as the percentage of cultures from pleural effusions and needle biopsies combined (39\%) (fig. 2). The higher yield of positive TB cultures more often allows susceptibility tests, which may have a considerable impact on the correct treatment and final outcome of therapy in patients with drug resistances $[65,66]$.

Although some authors are not overly concerned with long-term complications of tuberculous effusions [67], the positive role of early removal of the pleural fluid was shown recently in a double-blind, randomised, placebocontrolled trial from Taiwan [68]. In this study, it was demonstrated that early effective drainage, combined with complete antituberculous treatment, may hasten the clearance of pleural effusion, reduce the occurrence of residual pleural thickening, and accelerate pulmonary function recovery in patients with symptomatic loculated tuberculous pleural effusion. Medical thoracoscopy/pleuroscopy permits the combination of the diagnostic procedure with the drainage of all fluid, if necessary with opening of loculations, and can be used at least in countries with a low TB incidence $[42,63]$.

\section{Parapneumonic effusions and empyema}

There are only few publications on the use of medical thoracoscopy/pleuroscopy in the diagnosis and treatment of parapneumonic effusions and empyema $[9,14,20,69,70]$. In cases with multiple loculations, it is possible to open these spaces by removing fibrinopurulent membranes with the forceps and, thus, create one single cavity that can be drained and irrigated with high efficiency. This was demonstrated in a retrospective study on 127 patients of whom $94 \%$ were treated successfully for multiloculated empyema [7]]. 
Only $6 \%$ of the patients required a surgical approach. This treatment should be performed early in the course of parapneumonic effusion/ empyema, before the adhesions become too fibrinous and adherent. Thus, if the indication for placement of a chest tube is present and if the facilities are available, medical thoracoscopy/pleuroscopy should be performed at the time of chest-tube insertion. Overall, medical thoracoscopy/pleuroscopy is a procedure technically similar to chest-tube placement but it enables the creation of a single pleural cavity per mechanical opening of loculations and removal of fibrinous material, allowing successful local treatment. It is also recommended in patients who are unable to tolerate surgery $[72,73]$.

\section{Effusions of other origin}

In other pleural effusions, when the origin remains indeterminate, the main diagnostic value of medical thoracoscopy/pleuroscopy lies in its ability to exclude, with high probability, malignant and tuberculous disease $[42,45,46,74]$. In cases of pleural effusions that are neither malignant nor tuberculous, it may occasionally give macroscopic clues to their aetiology [18].

Medical thoracoscopy/pleuroscopy is helpful in differentiating between malignant and paramalignant pleural effusions in lung cancer $[26,61]$, and it is well suited for the diagnosis of benign, asbestos-related pleural effusions, which, by definition, present a diagnosis of exclusion $[18,46]$.

In some selective cases of recurrent pleural effusions of non-malignant aetiology, including chylothorax, hepatic effusions and refractory effusions due to cardiac aetiology or in systemic lupus erythematosus, talc poudrage during medical thoracoscopy/pleuroscopy has been successfully applied [75-77].

\section{Idiopathic pleural effusions}

When medical thoracoscopy/pleuroscopy is used in the diagnostic work-up of pleural effusions, the proportion of so-called idiopathic pleural effusions usually falls markedly below $10 \%$ [78-80], whereas studies in which medical thoracoscopy/pleuroscopy does not belong to the diagnostic armamentarium mostly report failure to obtain a diagnosis in over $20 \%$. Of note, the failure rate depends on the selection of patients and on the definition of idiopathic $[81,82]$. In follow-up studies after indeterminate thoracoscopic diagnoses, the most often missed diagnoses were malignant mesothelioma and malignant lymphoma [81-83]. The results after open thoracotomy are apparently not much superior, as shown in a study from the Mayo Clinic [84]. As already mentioned, autofluorescence video thoracoscopy or narrow-band imaging during semi-rigid pleuroscopy may help in future to avoid some of the falsenegative results [57-59]. However, repeated medical thoracoscopy/pleuroscopy is also feasible [85].

\section{Pleurodesis in chronic pleural effusions}

If the patient has a good performance status, consideration should be given to performing a pleurodesis for local treatment of malignant or other treatment-refractory pleural effusions $[46,75]$.

Thoracoscopic pleurodesis with talc insufflation (poudrage) offers several advantages for pleurodesis such as complete removal of pleural fluid, evaluation of the re-expansion potential of the lung by direct inspection, grading of intrapleural tumour spread and evaluation of remaining normal surface and homogeneous distribution of talc by insufflation under visual control [18, 41, 42, 46].

By using medical thoracoscopy/pleuroscopy, both diagnostic as well as therapeutic goals can be achieved in a single session $[15,18,26,37,61,86,87]$. In addition, it overcomes the limitation of chest-tube talc pleurodesis with slurry. The approach is also cost-saving in comparison to needle biopsy, since it avoids the need for separate insertion of a chest drain (after tests have confirmed the need to do this) as well as the need for adequate drainage before administering a sclerosant to achieve a pleurodesis [47], which is usually not as effective as via medical thoracoscopy/pleuroscopy, especially if from lung or breast cancer [88]. Overall complications from thoracoscopic talc pleurodesis are relatively small and it could be demonstrated in a prospective multicentre study in $558 \mathrm{pa}$ tients with malignant pleural effusion that medical thoracoscopic poudrage with a largeparticle talc did not cause ARDS [89] as seen in several studies which used small-particle talc [90]. In order to discharge the patients early, it 
was shown recently that the combination of medical thoracoscopy/pleuroscopy with an indwelling catheter placed at the end of thoracoscopy works well [91].

In addition, talc may have a direct effect on the malignant tumour cells, such as initiation of the events leading to programmed death of the tumour cell (apoptosis) [92]. Furthermore, talc has been shown to alter the angiogenic balance in the pleural space from a biologically active and angiogenic environment to an angiostatic milieu [93].

\section{Pneumothorax}

A number of therapeutic options are available for treatment of primary spontaneous pneumothorax, varying from conservative (observation, oxygen treatment, simple manual aspiration, small-catheter drainage) through intermediately invasive (chest-tube drainage, medical thoracoscopic talc poudrage, or pleural abrasion) to invasive measures (VATS with blebectomy or bullectomy, pleural abrasion or partial pleurectomy, or axillary thoracotomy) [94].

There is good consensus and clinical evidence that a recurrence prevention of pulmonary spontaneous pneumothorax should be proposed only after first recurrence, based on the observation that recurrence occurs in only one-third of patients, but may increase to $62 \%$ after first recurrence, and to $83 \%$ after third [95]. The choice between medical thoracoscopy/pleuroscopy, surgical thoracoscopy (VATS), or open surgery as method of access to the pleural cavity depends on the professional background of the operator (chest physician or surgeon), and on local availabilities, preferences, beliefs and habits [18]. Of great importance is that a good pleurodesis is achieved, which is possible by thoracoscopic talc poudrage [17, 18]. The short-term safety was recently shown, too [96].

Secondary spontaneous pneumothorax, caused by several underlying lung disorders, most frequently in COPD, may present as a potential life-threatening disease because lung function in these patients is already compromised. Treatment usually requires immediate action, and thoracoscopic talc poudrage is an excellent option in these patients with a higher operative risk [95].

\section{Diffuse lung diseases}

Forceps lung biopsies taken during medical thoracoscopy/pleuroscopy have been shown to be quite efficient, the technique has been used for many years by chest physicians $[17,18$, 20, 97]. However, the indications for thoracoscopic/pleuroscopic lung biopsies in diffuse lung diseases have substantially decreased [42]. The decrease is due to the improved diagnostic results of bronchoscopy using transbronchial lung biopsies and bronchoalveolar lavage, as well as to the development of high-resolution CT (HRCT). However, medical thoracoscopy and lung biopsies are suitable options for those who are familiar with the technique, which is easy and safe. The advantage of medical thoracoscopy is that it is less invasive than VATS, using local anaesthesia and no intubation. In comparison with bronchoscopy, medical thoracoscopy/pleuroscopy is more invasive but presents several advantages. It provides significantly larger samples and allows the physician to choose the biopsy site, at least three biopsy samples should be taken. In the largest published series of 585 cases an overall sensitivity of $86 \%$ was found varying between $96 \%$ in sarcoidosis and $42 \%$ in Langerhans cell histiocytosis [98]. A disadvantage is the longer drainage time, which has been shown to be related to the stiffness of the lung [99].

\section{Other indications}

Medical thoracoscopy/pleuroscopy will most often be used in the diagnosis and treatment of pleural exudates, recurrent pleural transudates, and spontaneous pneumothorax [42, $45,100,101]$. With increasing expertise, other indications may follow: lung biopsies, empyema, diffuse pleural thickening or pleural tumours [37]. In some instances, trained medical thoracoscopists will also tackle other clinical problems [18]. These include interventions at the sympathetic chain (sympathectomy, e.g., for the treatment of essential hyperhidrosis [102]; splanchnicectomy, e.g. for the treatment of chronic pancreatic pain) [103] and pericardial fenestration for the treatment of pericardial tamponades $[18,104]$.

Medical thoracoscopy/pleuroscopy is also a valuable tool for research in pleural diseases [18]. 


\section{References}

1. Jacobaeus HC. Über die Möglichkeit, die Zystoskopie bei Untersuchung seröser Höhlungen anzuwenden. Münch med Wschr 1910; 57: 2090-2092.

2. Seijo LM, Sterman DH. Interventional pulmonology. N Engl J Med 2001; 344: 740-749.

3. Hoksch B, Birken-Bertsch H, Müller JM. Thoracoscopy before Jacobaeus. Ann Thorac Surg 2002; 74: 1288-1290.

4. Cruise FR. The endoscope as an aid to the diagnosis and treatment of disease. Br Med J 1865; 8: 345-347.

5. Gordon S. Clinical reports of rare cases, occurring in the Whitworth and Hartwicke Hospitals: most extensive pleuritic effusion rapidly becoming purulent, paracentesis, introduction of a drainage tube, recovery, examination of interior of pleura by the endoscope. Dublin Quarterly Journal of Medical Science 1866; 41: 83-90.

6. Marchetti GP, Pinelli V, Tassi GF. 100 years of thoracoscoy: historical notes. Respiration 2011; 82: 187-192.

7. Moisiuc FV, Colt HG. Thoracoscopy: origins revisited. Respiration 2007; 74: 344-355.

8. Jacobaeus HC. Über Laparo- und Thorakoskopie. Beitr Klin Tuberk 1912; 25: 185-354.

9. Jacobaeus HC. Die Thorakoskopie und ihre praktische Bedeutung. Ergebn ges Med 1925; 7: 112-166.

10. Jacobaeus HC. The cauterization of adhesions in artificial pneumothorax therapy of tuberculosis. Amer Rev Tuberc 1922; 6: 871-897.

11. Brandt HJ, Loddenkemper R, Mai J. Atlas of diagnostic thoracoscopy. Indications - Technique. New York, Thieme Inc., 1985.

12. Sattler A. Zur Behandlung des Spontanpneumothorax mit besonderer Berücksichtigung der Thorakoskopie. Beitr Klin Tuberk 1937; 89: 395-408.

13. Kux E. Thorakoskopische Eingriffe am Nervensystem. Stuttgart, Thieme; 1954.

14. Weissberg D. Pleuroscopy in empyema: is it ever necessary? Poumon 1981; 37: 269-272.

15. Roche G, Delanoe Y, Moayer N. Talcage de la plèvre sous pleuroscopie. Résultats, indications, technique (A propos de 14 observations). J Fr Med Chir Thorac 1963; 21: 177-195.

16. Medford AR, Bennett JA, Free CM, et al. Current status of medical pleuroscopy. Clin Chest Med 2010; 31: 165-172.

17. Tschopp JM, Rami-Porta R, Noppen M, et al. Management of spontaneous pneumothorax: state of the art. Eur Respir J 2006; 28: 637-650.

18. Loddenkemper R, Mathur PN, Noppen M, Lee P. Medical Thoracoscopy/Pleuroscopy. Manual and Atlas. Stuttgart New York, Thieme, 2011.

19. Swierenga J, Wagenaar JPM, Bergstein PGM. The value of thoracoscopy in the diagnosis and treatment of diseases affecting the pleura and lung. Pneumonologie 1974; 151: 11-18.

20. Boutin C, Viallat JR, Aelony Y. Practical thoracoscopy. Berlin Heidelberg New York, Springer, 1991.

21. Lewis JW Jr. Thoracoscopy: A surgeon's or a pulmonologist's domain. Pro pulmonologist. J Bronchol 1994; 1: 152-156.

22. Boutin C, Loddenkemper R, Astoul P. Diagnostic and therapeutic thoracoscopy: techniques and indications in pulmonary medicine. Tuber Lung Dis 1999; 74: 225-239.

23. Mathur PN, Boutin C, Loddenkemper R. Medical thoracoscopy: Techniques and indications in pulmonary medicine. J Bronchol Intervent Pulmonol 1994; 1: 228-238.

24. Weissberg D. Handbook of practical pleuroscopy. Mount Kisko, Futura, 1991.

25. Piquet A, Giraud A. La pleuroscopie et la section des adhérences intrapleural au cours du pneumothorax thérapeutique. La presse médicale. 1923; 23.

26. Rodriguez-Panadero F, Janssen JP, Astoul P. Thoracoscopy: general overview and place in the diagnosis and management of pleural effusion. Eur Respir J 2006; 28: 409-422.

27. Buchanan DR, Neville E. Thoracoscopy for Physicians: A Practical Guide. London, Arnold, 2004.

28. Rahman NM, Ali NJ, Brown G, et al. Local anaesthetic thoracoscopy: British Thoracic Society pleural disease guideline 2010. Thorax 2010; 65: Suppl. 2, ii54-ii6o.

29. Oldenburg FA Jr, Newhouse MT. Thoracoscopy. A safe, accurate diagnostic procedure using the rigid thoracoscope and local anesthesia. Chest 1979; 75: 45-50.

30. Davidson AC, George RJ, Sheldon CD, et al. Thoracoscopy: assessment of a physician service and comparison of a flexible bronchoscope used as a thoracoscope with a rigid thoracoscope. Thorax 1988; 43: 327-332.

31. Takeno Y. Thoracoscopic treatment of spontaneous pneumothorax. Ann Thorac Surg 1993; 56: 688-69o.

32. McLean AN, Bicknell SR, McAlpine LG, et al. Investigation of pleural effusion: an evaluation of the new Olympus LTF semiflexible thoracofiberscope and comparison with Abram's needle biopsy. Chest 1998; 114: 150-153.

33. Ernst A, Hersh CP, Herth $F$, et al. A novel instrument for the evaluation of the pleural space: an experience in 34 patients. Chest 2002; 122: 1530-1534.

34. Munavvar M, Khan MA, Edwards J, et al. The autoclavable semirigid thoracoscope: the way forward in pleural disease? Eur Respir J 2007; 29: 571574 .

35. Lee $\mathrm{P}$, Colt HG. Rigid and semirigid pleuroscopy: the future is bright. Respirology 2005; 10: 418-425.

36. Loddenkemper R. Medical Thoracoscopy/ Pleuroscopy: step by step. Breathe 2011; 8: 156-168.

37. Tassi GF, Davies RJ, Noppen M. Advanced techniques in medical thoracoscopy. Eur Respir J 2006; 28: 1051-1059.

38. Tassi G, Marchetti G. Minithoracoscopy: a less invasive approach to thoracoscopy. Chest 2003; 124: 1975-1977.

39. Tassi GF, Marchetti GP, Pinelli V. Minithoracoscopy: a complementary technique for medical thoracoscopy. Respiration 2011; 82: 204-206.

40. Janssen JP, Thunissen FBJM, Visser FJ. Comparison of the $2.0 \mathrm{~mm}$ and $3.5 \mathrm{~mm}$ minithoracoscopy set to standard equipment for medical thoracoscopy. Eur Respir J 2003; 22: Suppl. 45, S541.

41. Harris RJ, Kavuru MS, Rice TW, et al. The diagnostic and therapeutic utility of thoracoscopy. A review. Chest 1995; 108: 828-841.

42. Loddenkemper R. Thoracoscopy - state of the art. Eur Respir J 1998; 11: 213-221.

43. Casal RF, Eapen GA, Morice RC, et al. Medical thoracoscopy. Curr Opin Pulm Med 2009; 15: 313-320.

44. Lee P, Mathur PN, Colt HG. Advances in thoracoscopy: 100 years since Jacobaeus. Respiration 2010; 79: $177-186$. 
45. Janssen JP. Why you do or do not need thoracoscopy. Eur Respir Rev 2010; 19: 213-216.

46. Antony VB, Loddenkemper R, Astoul $\mathrm{P}$, et al. Management of malignant pleural effusions. (ATS/ ERS Statement). Eur Respir J 2001; 18: 402-419.

47. Medford AR. Theoretical cost benefits of medical thoracoscopy (MT). Respir Med 2010; 104: 10751076.

48. Boutin C, Viallat JR, Cargnino P, et al. Thoracoscopy in malignant pleural effusions. Am Rev Respir Dis 1981; 124: 588-592.

49. Schwarz C, Lübbert H, Rahn W, et al. Medical thoracoscopy: hormone receptor content in pleural metastases due to breast cancer. Eur Respir J 2004; 24: 728-730.

50. Steiropoulos P, Kouliatsis G, Karpathiou G, et al. Rare cases of primary pleural Hodgkin and nonHodgkin lymphomas. Respiration 2009; 77: 459-463.

51. Schwarz C, Bittner R, Kirsch A, et al. A 62-year-old woman with bilateral pleural effusions and pulmonary infiltrates caused by extramedullary hematopoiesis. Respiration 2009; 78: 110-113.

52. Colt HG. Thoracoscopic management of malignant pleural effusions. Clin Chest Med 1995; 16: 505-518.

53. Boutin C, Rey F. Thoracoscopy in pleural malignant mesothelioma: a prospective study of 188 consecutive patients. Part 1: Diagnosis. Cancer 1993; 72: 389393.

54. Scherpereel A, Astoul P, Baas P, et al. Guidelines of the European Respiratory Society and the European Society of Thoracic Surgeons for the management of malignant pleural mesothelioma. Eur Respir J 2010; 35: 479-495.

55. Boutin C, Viallat JR, Aelony Y. Practical thoracoscopy. Berlin Heidelberg New York, Springer, 1991.

56. Loddenkemper R, Boutin C. Thoracoscopy: present diagnostic and therapeutic indications. Eur Respir J 1993; 6: 1544-1555.

57. Chrysanthidis MG, Janssen PJ. Autofluorescence videothoracoscopy in exudative pleural effusions: preliminary results. Eur Respir J 2005; 26: 989-992.

58. Schönfeld N, Schwarz J, Kollmeier J, et al. Narrow band imaging (NBI) during medical thoracoscopy: first impressions. J Occup Med Toxicol 2009; 4: 2428.

59. Ishida A, Ishikawa F, Nakamura M, et al. Narrow band imaging applied to pleuroscopy for the assessment of vascular patterns of the pleura. Respiration 2009; 78: 432-439.

6o. Froudarakis ME. New challenges in medical thoracoscopy. Respiration 2011; 82: 197-200.

61. Roberts ME, Neville E, Berrisford RG, et al. Management of a malignant pleural effusion: British Thoracic Society Pleural Disease Guideline 2010. Thorax 2010; 65: Suppl. 2, ii32-ii40.

62. Rodriguez-Panadero F, Antony VB. Pleurodesis. State of the art. Eur Respir J 1997; 10: 1648-1654.

63. Diacon AH, Van de Wal BW, Wyser C, et al. Diagnostic tools in tuberculous pleurisy: a direct comparative study. Eur Respir J 2003; 22: 589-591.

64. Loddenkemper R, Grosser H, Mai J, et al. Diagnosis of tuberculous pleural effusion: prospective comparison of laboratory chemical, bacteriologic, cytologic, and histologic study results. Prax Klin Pneumol 1983; 37: 1153-1156.

65. Baumann MH, Nolan R, Petrini M, et al. Pleural tuberculosis in the United States: incidence and drug resistance. Chest 2007; 131: 1125-1132.

66. Hooper C, Lee YCG, Maskell N. Investigation of a unilateral pleural effusion in adults: British Thoracic Society pleural disease guidelines 2010 . Thorax 2010; 65: Suppl. 2, ii4-17.

67. Sahn SA. Pleural thickening, trapped lung, and chronic empyema as sequelae of tuberculous pleural effusion: don't sweat the pleural thickening. Int J Tuberc Lung Dis 2002; 6: 461-464.

68. Chung $\mathrm{CL}$, Chen $\mathrm{CH}$, Yeh CY, et al. Early effective drainage in the treatment of loculated tuberculous pleurisy. Eur Respir J 2008; 31: 1261-1267.

69. Solèr M, Wyser C, Bolliger CT, et al. Treatment of early parapneumonic empyema by "medical" thoracoscopy. Schweiz Med Wochenschr 1997; 127: 17481753.

70. Loddenkemper R, Kaiser D, Frank W. Treatment of parapneumonic pleural effusion and empyema conservative view. Eur Respir Mon 2004; 29: 199207.

71. Brutsche MH, Tassi GF, Györik S, et al. Treatment of sonographically stratified multiloculated thoracic empyema by medical thoracoscopy. Chest 2005; 128: 3303-3309.

72. Kern L, Robert J, Brutsche M. Management of parapneumonic effusion and empyema: medical thoracoscopy and surgical approach. Respiration 2011; 82: 193-196.

73. Karmy-Jones R, Sorenson V, Horst HM, et al. Rigid thoracoscopic debridement and continuous pleural irrigation in the management of empyema. Chest 1997; 111: 272-274.

74. Light RW. The undiagnosed pleural effusion. Clin Chest Med 2006; 27: 309-319.

75. Sudduth C, Sahn SA. Pleurodesis for non-malignant pleural effusions. Recommendations. Chest 1992; 102: 1855-1860.

76. Mares CC, Mathur PN. Medical thoracoscopic talc pleurodesis for chylothorax due to lymphoma: a case series. Chest 1998; 114: 731-735.

77. Breuer GS, Deeb M, Fisher D, et al. Therapeutic options for refractory massive pleural effusion in systemic lupus erythematosus: a case study and review of the literature. Semin Arthritis Rheum 2005; 34: 744-749.

78. Canto A, Blasco E, Casillas M, et al. Thoracoscopy in the diagnosis of pleural effusion. Thorax 1977; 32: 550-554.

79. Loddenkemper R. Thoracoscopy: results in noncancerous and idiopathic pleural effusion. Poumon Coeur 1981; 37: 261-264.

8o. Martensson G, Petersson K, Thiringer G. Differentiation between malignant and non-malignant pleural effusion. Eur J Respir Dis 1985; 67: 326334 .

81. Janssen JP, Ramlal S, Mravunac M. The long-term follow-up of exudative pleural effusion after nondiagnostic thoracoscopy. J Bronchol 2004; 11: 169174 .

82. Venekamp LN, Velkeniers B, Noppen M. Does 'idiopathic pleuritis' exist? Natural history of nonspecific pleuritis diagnosed after thoracoscopy. Respiration 2005; 72: 74-78.

83. Davies HE, Nicholson JE, Rahman NM, et al. Outcome of patients with nonspecific pleuritis/ fibrosis on thoracoscopic pleural biopsies. Eur J Cardiothorac Surg 2010; 38: 472-477.

84. Ryan CJ, Rodgers RF, Unni KK, et al. The outcome of patients with pleural effusion of indeterminate cause at thoracotomy. Mayo Clin Proc 1981; 56: 145-149.

85. Breen D, Fraticelli $A$, Greillier $L$, et al. Redo medical thoracoscopy is feasible in patients with pleural diseases - a series. Interact Cardiovasc Thorac Surg 2009; 8: 330-333.

86. Michaud G, Berkowitz DM, Ernst A. Pleuroscopy for diagnosis and therapy for pleural effusions. Chest 2010; 138: 1242-1246.

87. Tschopp JM, Schnyder JM, Astoul P, et al. Pleurodesis by talc poudrage under simple medical thoracoscopy: an international opinion. Thorax 2009; 33: $442-443$. 
88. Dresler CM, Olak J, Herndon JE 2nd, et al. Phase III intergroup study of talc poudrage vs talc slurry sclerosis for malignant pleural effusion. Chest 2005; 127: 909-915.

89. Janssen JP, Collier G, Astoul P, et al. Safety of pleurodesis with talc poudrage in malignant pleural effusion: a prospective cohort study. Lancet 2007; 369: 1535-1539.

90. Gonzalez AV, Bezwada V, Beamis Jr JF, et al. Lung injury following thoracoscopic talc insufflation: experience of a single North American center. Chest 2010; 137: 1375-1381.

91. Reddy C, Ernst A, Lamb C, et al. Rapid pleurodesis for malignant pleural effusions. A pilot study. Chest 2011; 139: 1419-1423.

92. Nasreen N, Mohammed KA, Dowling PA, et al. Talc induces apoptosis in human malignant mesothelioma cells in vitro. Am J Respir Crit Care Med 2000; 161: 595-600.

93. Nasreen N, Mohammed KA, Brown S, et al. Talc mediates angiostasis in malignant pleural effusions via endostatin induction. Eur Respir J 2007; 29: 761769 .

94. Noppen M, De Keukeleire T. Pneumothorax. Respiration 2008; 76: 121-127.

95. Baumann MH, Noppen M. Pneumothorax. Respirology 2004; 9: 157-164.

96. Bridevaux PO, Tschopp JM, Cardillo G, et al. Shortterm safety of thoracoscopic talc pleurodesis for recurrent primary spontaneous pneumothorax: a prospective European multicentre study. Eur Respir J 2011; 38: 770-773.

97. Brandt HJ. Pulmonary biopsy under visual control. Poumon Coeur 1981; 37: 307-311.

98. Schaberg T, Süttmann-Bayerl A, Loddenkemper R. Thoracoscopy in diffuse lung diseases. Pneumologie 1989; 43: 112-115.

99. Vansteenkiste J, Verbeken E, Thomeer M, et al. Medical thoracoscopic lung biopsy in interstitial lung disease: a prospective study of biopsy quality. Eur Respir J 1999; 14: 585-590.

100. Froudarakis ME. Diagnostic work-up of pleural effusions. Respiration 2008; 75: 4-13.

101. Tschopp JM, Boutin C, Astoul P, et al. Talcage by medical thoracoscopy for primary spontaneous pneumothorax is more cost-effective than drainage: a randomised study. Eur Respir J 2002; 20: 1003-1009.

102. Noppen M, Dendale P, Hagers Y. Thoracoscopic sympathectomy. Lancet 1995; 345: 803-804.

103. Noppen M, Meysman M, D'Haese J, et al. Thoracoscopic splanchnicolysis for the relief of chronic pancreatitis pain: experience of a group of pneumologists. Chest 1998; 113: 528-531.

104. Vogel B, Mall W. Thorakoskopische Perikardfensterung - diagnostische und therapeutische Aspekte. Pneumologie 1990; 40: $184-185$. 